\title{
Stability Of Money Multipliers: Evidence From Turkey
}

Cem Saatcioglu, University of Istanbul, Turkey

H.Levent Korap, Marmara University, Turkey

Ara G. Volkan, (E-mail: avolkan@fgcu.edu), Florida Gulf Coast University

\begin{abstract}
This paper investigates whether the money multiplier process in the Turkish economy is stable and can be forecasted. Research results show that the processes which convert the base money supply into the final monetary aggregates are unstable and decrease the effectiveness of monetary policies pursued by the CBRT. In addition, the sub-components of the money multiplier do not support a stable money multiplier process, indicating that traditional monetarist prescriptions for the conduct of economic policy are not appropriate for the Turkish economy.
\end{abstract}

\section{INTRODUCTION}

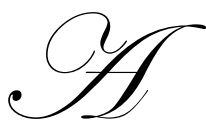

ccording to the monetary theory pioneer Friedman (1968: 14), proper implementation of monetary policy requires that the monetary authority target only the magnitudes of variables it can control. Decades of research in developed countries concerning this prescription points out that the control of monetary aggregates is the best available policy tool. Thus, in policy regimes that target the levels of monetary stocks, the monetary authority must be able to control the quantity of money stock supplied and forecast the changes in the factors that affect the resulting money supply to ensure the stability of its monetary regime (Paya, 1998: 167).

Under the above mentioned conditions, monetary targeting would be an appropriate policy regime in an inflationary environment if a long run relationship between the changes in the money stock and changes in the price level exists, provided that the direction of the causality extends from the money stock changes to the price changes. If a bi-directional causality occurs, the monetary authority cannot control the money supply. In this case, monetary aggregates would be endogenous to the monetary regime and out of the control of the monetary authority. In addition, other economic variables may impact the money stock and cause the final monetary aggregates be endogenous to the monetary regime.

Since controlling the changes in monetary aggregates is a basic requirement of the monetary theory, effective policy making requires that stable relationships exist between these aggregates. The base money stock provided by the monetary authority is multiplied through the banking system creating additional deposits that become the major components of the final money supply (Begg, Fischer and Dornbusch, 1994: 402). This money multiplier process describes how the final monetary aggregates are determined in an economy and establishes the relationship between the changes in the final money supply for a given change in the monetary base. Since other economic variables may also impact the final money supply (Mishkin, 1997: 436), the stability of the money multiplier process must be established so that the impact of a controlled change in base money stock on the final monetary aggregates can be separated from the impact resulting from changes in endogenous economic variables (Keyder, 1998: 248).

\section{PURPOSE}

This study first examines the stability of various money multiplier processes in the Turkish economy during the 1990-2004 period following the methodology used by Şahinbeyoğlu (1995: 1-10). This approach empirically tests the models best describing the multiplier process for the stationary characteristics required and uses co-integration estimation techniques to reveal the relationships between the base and final money supply aggregates. In addition, the study aims to reveal the relationships that may exist between the sub-components of the money multiplier process. If 
the multiplier process and its sub-components are stable and the relationships between base money stock and final money supply aggregates can be determined, the monetary theory prescriptions that are successfully implemented in developed countries can be similarly applied to developing economies.

\section{METHODLOGY}

\section{A Money Multiplier Model For The Turkish Economy: Identifying Basic Model Variables}

In constructing a model for the multiplier process, we first the money supply $\left(M_{s}\right)$ is specified as the sum of the cash held by the non-bank private sector $(C)$ and the deposits of the banking system $(D)$,

$M_{s}=C+D$

Next, the base money stock $(B)$ is defined as the sum of the net liabilities or reserves of the Central Bank of the Republic of Turkey (CBRT) held by either the non-bank private sector $(R P)$ or banks $(R B)$,

$B=R P+R B$

Multiplying both sides of equation (1) by $B /(R P+R B)$ would give,

$M_{s}=[(C+D) /(R P+R B)] * B$

Further multiplying both the numerator and the denominator of the term in the square brackets by $1 / D$, we will have the following identities,

$M_{s}=[(1+C / D) /(R P / D+R B / D)] * B$

$\mathrm{M}_{\mathrm{s}}=[(1+c) /(p+b)] * B$

$M_{s}=k * B$

$k=M_{s} / B$

In equations (4) and (5), $c$ is the ratio of the non-bank private sector cash to banking deposits and $p$ and $b$ indicate the reserves to deposit assets ratios of the non-bank private sector and the commercial banks, respectively. In equation (4), $k$ equals to $[(1+c) /(p+b)]$ and represents the money multiplier, indicating that the changes in money supply $\left(M_{s}\right)$ result from the changes in monetary base $(B)$ and the changes in the value of the multiplier $(k)$. Thus, for a stable and predictable relationship between the monetary base and the monetary aggregates originating from this base, $\left(M_{s} / B\right)$ in equation (5) is expected to be stationary. To test this hypothesis, equation (5) can be rearranged in a logarithmic scale to obtain,

$\ln k=\ln M_{s}-\ln B$

A long run co-integration relationship between the money supply and the monetary base exists even when $k$ is unstable but the co-integrating parameter is equal to one, the latter indicating that $M_{s}$ and $B$ have the same order of integration and trend together.

\section{Test Variable Definitions, Sources Of Data, And Time Series Properties Of The Money Multipliers Used}

The time series representations of the money multipliers and log-scaled variables used are shown in Table 1. The prefix $L N$ indicates the natural logarithm operator. The variable $R M$ is defined as the reserve money which is the sum of currency issued, deposits of the banking sector kept as required reserves and free deposits, and the funds and deposits of the non-bank sector. The variable $M B$ is the central bank money, which is the sum of $R M$ and the funds obtained through open market operations and new Turkish lira (YTL) deposits of the public sector, all obtained from the analytical balance sheet of the CBRT. MI consists of the sum of the currency in circulation and demand deposits in the banking system, while $M 2$ is $M 1$ plus time deposits in domestic currency (YTL). Also, $M 2 Y$ equals $M 2$ 
Table 1: Time Series Used In The Paper

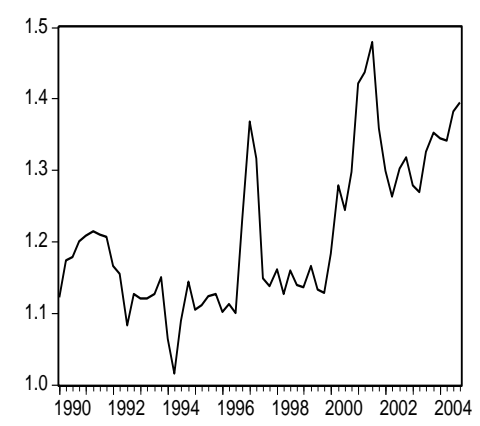

- K1RM
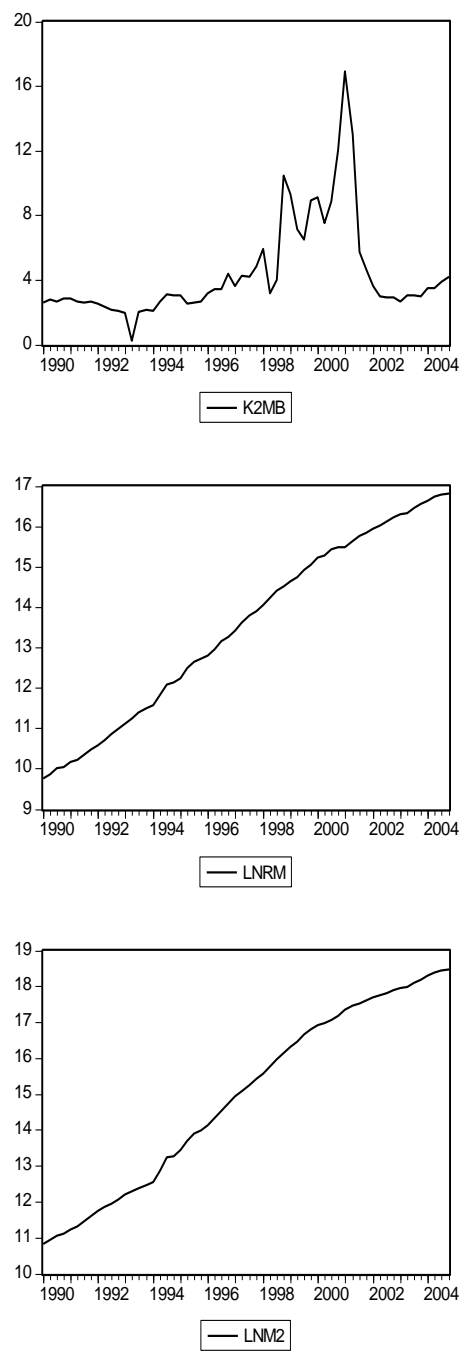

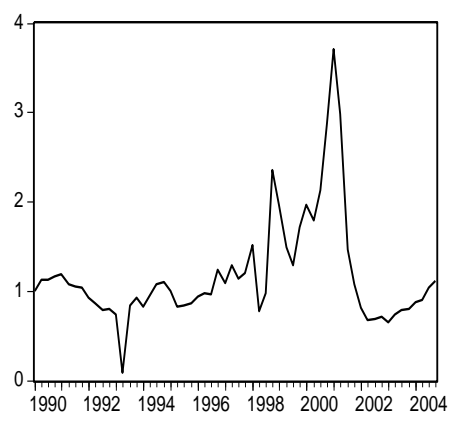

$-\mathrm{K} 1 \mathrm{MB}$
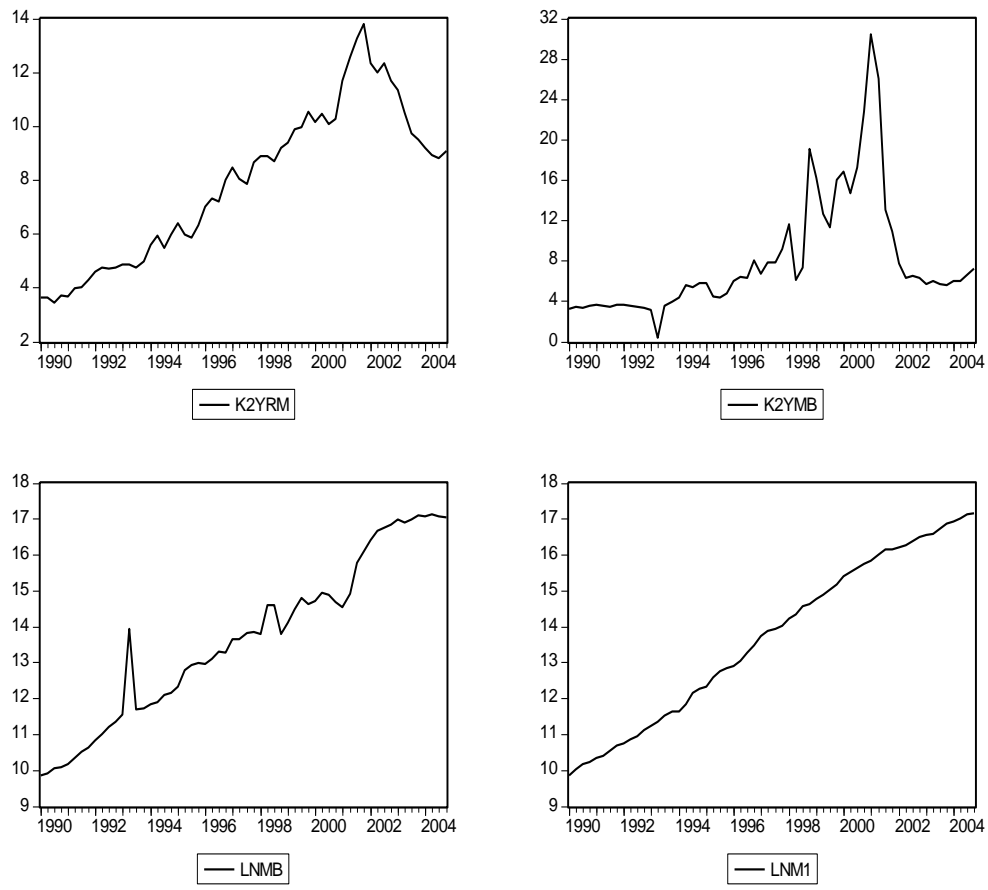

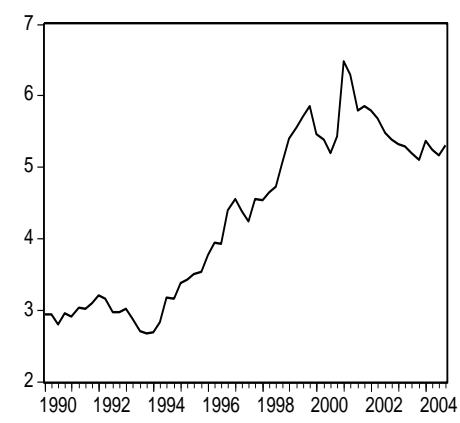

$-\mathrm{K} 2 \mathrm{RM}$

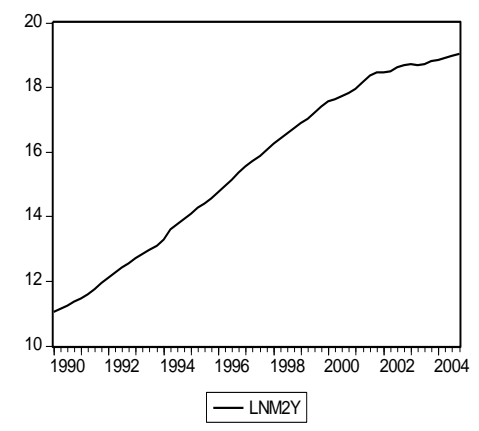


plus deposits denominated in foreign currencies, all obtained from the electronic data delivery system of the CBRT. $K 1 R M$ and $K 1 M B$ are the money multipliers that are calculated by dividing the (MI) money supply with reserve money $(R M)$ and central bank money $(M B)$, respectively. A similar calculation is used to obtain the money multipliers $K 2 R M$ and $K 2 M B$, using the money supply $M 2$, and, $K 2 Y R M$ and $K 2 Y M B$, using the money supply $M 2 Y$.

\section{Models For Stability Tests}

To develop models for stability tests, the root theory presented in Eviews 5 User's Guide by QMS (2004: $505-507)$ is used. Let us consider a simple $A R(1)$ process,

$y_{t}=\rho y_{t-1}+x_{t}{ }^{\prime} \delta+\varepsilon_{t}$

where $x_{t}$ are the optional exogenous regressors which may consist of either a constant or a constant and a trend and $\rho$ and $\delta$ are the parameters to be estimated. In addition, the $\varepsilon_{t}$ terms are assumed to be white noise. If $|\rho| \geq 1, y$ is a nonstationary series and the variance of $y$ increases with time and approaches infinity. If $|\rho|<1, y$ is a trend-stationary series. Thus, the hypothesis of trend-stationarity can be evaluated by testing whether the absolute value of $\rho$ is strictly less than one.

The unit root models considered in this paper test the null hypothesis of $H_{0}: \rho=1$ against the one-sided alternative of $H_{l}: \rho<1$. Estimating equation (7) after subtracting $y_{t-1}$ from both sides of the equation results in,

$\Delta y_{t}=\alpha y_{t-1}+x_{t}{ }^{\prime} \delta+\varepsilon_{t}$

where $\alpha=\rho-1$. The null and alternative hypotheses are written as,

$H_{0}: \alpha=0$ and $H_{1}: \alpha<0$

and evaluated using the conventional $t$-ratio for $\alpha$,

$t_{\alpha}=E(\alpha) /[\operatorname{se}(E(\alpha))]$

where $E(\alpha)$ is the estimate of $\alpha$ and $\operatorname{se}(E(\alpha))$ is the standard error coefficient.

Dickey and Fuller (1979: 427-431) show that when testing the null hypothesis under the unit root theory, the statistic does not follow the conventional Student's $t$-distribution. They derive asymptotic results and simulate critical values for various test and sample sizes. More recently, MacKinnon (1996: 601-618) implements a much larger set of simulations than those tabulated by Dickey and Fuller. The more recent MacKinnon critical value calculations used in this paper are also available in Eviews 5.0.

The simple Dickey-Fuller unit root test described above is valid only if the series is an $A R(1)$ process. If the series is correlated at higher order lags, the assumption of white noise disturbances $\varepsilon_{t}$ is violated. The Augmented Dickey-Fuller (ADF) test constructs a parametric correction for higher-order correlation by assuming that the $y$ series follows an $A R(p)$ process and adding $p$ lagged difference terms of the dependent variable $y$ to the right-hand side of the test regression,

$\Delta y_{t}=\alpha y_{t-1}+x_{t}{ }^{\prime} \delta+\beta_{1} \Delta y_{t-1}+\beta_{2} \Delta y_{t-2}+\ldots . .+\beta_{\mathrm{p}} \Delta y_{t-p}+v_{t}$

This augmented specification is then used to test equation (9) using the $t$-ratio in equation (10). The critical issue in this analysis is the number of lagged differenced terms to be added to test the regression. In this study, a sufficient number of lags are added to remove the serial correlations that may exist in the residuals. In addition, the Phillips-Perron (PP) test is used to test the sufficiency of the lags added. Phillips and Perron (1988: 335-346) propose an alternative (non-parametric) method of controlling for serial correlation when testing for a unit root. The PP 
method estimates the non-augmented DF test equation in (8) and modifies the $t$-ratio of the $\alpha$ coefficient so that serial correlation does not affect the asymptotic distribution of the test statistic. The asymptotic distribution of the PP modified $t$-ratio is the same as the ADF statistic.

Thus, the ADF and PP unit root tests are used in this study to check for the stationarity condition of the model variables by comparing the ADF statistics and adjusted $t$-statistics obtained with the MacKinnon (1996: 601618) critical values. For the case of stationarity, these statistics are expected to be larger than the MacKinnon critical values in absolute value and to have a minus sign. Although differencing eliminates the trend, the test reports the results of the unit root tests for the first differences of the variables, with a linear time trend in the test regression. For the MacKinnon critical values, $\% 1$ and $\% 5$ level critical values are considered for the null hypothesis of a unit root. The numbers in parantheses are the lags used for the ADF stationary test and augmented up to a maximum of 12 lags, while the Newey-West bandwidths are used for the PP test. The choice of the optimum lag for the ADF test is selected to minimize the Schwarz Information Criterion (SC). The test statistics and the critical values are derived from the ADF or UNITROOT procedures described in Eviews 5.0. ADF is the augmented Dickey-Fuller test with critical values based on MacKinnon (1996: 601-618). A statistically significant test statistic rejects the null hypothesis in favor of stationarity. The notations * and ** indicate the rejection of the null hypothesis of a unit root at the $\% 1$ and $\% 5$ levels, respectively. All computer outputs reported in this paper are available from the authors upon request.

\section{Models For Co-Integration Tests}

Engle and Granger (1987: 251-276) indicate that even though economic time series may be non-stationary in their level forms, there exist linear combinations of these variables that converge to a stable relationship in the long run. If the series are individually stationary only after differencing and a linear combination of their levels is stationary, then the series are said to be co-integrated. That is, they move in tandem and cannot move too far away from each other (Dickey, Jansen and Thornton, 1991: 58). To test for a long run relationship between variables, a contemporaneous vector auto-regression (VAR) based co-integration methodology developed in Johansen (1991: 1551-1580) and Johansen (1995) is used.

Consulting Eviews 5 User's Guide by QMS (2004: 735-748), a VAR of order $p$ is assumed,

$y_{t}=A_{1} y_{t-1}+\ldots+A_{p} y_{t-p}+B x_{t}+\varepsilon_{t}$

where $y_{t}$ is a $k$-vector of non-stationarity $I(1)$ variables; $x_{t}$ is a $d$-vector of deterministic variables representing a constant term, a linear trend, and seasonal dummies; and $\varepsilon_{t}$ is a vector of innovations. Next, this VAR can be rearranged as,

$$
\Delta y_{t}=\Pi y_{t-1}+\sum_{i=1}^{p-1} \Gamma_{i} \Delta y_{t-i}+B x_{t}+\varepsilon_{t}
$$

where,

$$
\Pi=\sum_{i=1}^{p} A_{-}-I \quad \text { and } \quad \begin{array}{r}
p \\
\Gamma_{i}=-\sum A_{j} \\
j=i+1
\end{array}
$$

Granger representation theorem asserts that if the coefficient matrix $\Pi$ has a reduced rank $r<k$, then there exist $k x r$ matrices $\alpha$ and $\beta$ each with rank $r$ such that $\Pi=\alpha \beta^{\prime}$ and $\beta^{\prime} y_{t}$ is $I(0)$. In this relationship, $r$ is the number of cointegrating relations (the rank) and each column of $\beta$ is the co-integrating vector. The elements of $\alpha$ are known as the adjustment parameters in the vector error correction (VEC) model and measure the speed of adjustment of the variables examined with respect to a disturbance in the equilibrium relationship. Johansen's method is to estimate the $\Pi$ matrix from an unrestricted VAR and to test whether the restrictions implied by the reduced rank of $\Pi$ can be rejected. This method performs better than other estimation methods even when the errors have non-normal 
distributions or when the dynamics are unknown and the model is over-parameterized by including additional lags (Gonzalo, 1994: 225).

This study uses unrestricted VAR models with a maximum lag number of 8 and quarterly data to develop bivariate co-integrating equations. This lag number is chosen to minimize the Akaike's information criterion (AIC).

\section{RESULTS}

\section{Unit Root Tests For Stability}

The results for the study period 1990:1 - 2004:4 are shown in Tables 2 and 3. The ADF unit root tests indicate that the null hypothesis cannot be rejected for any of the variables except for $K 1 M B$ and $L N M B$, using both the constant and constant $\&$ trend terms in the test equation in the level form. In contrast, for the first differences, for all variables except the variable $L N R M$, the null hypothesis of a unit root is rejected at $1 \%$ confidence level (for the variable $L N M 2 Y$ the null hypothesis is rejected at the $5 \%$ level by considering a trend effect only).

The PP test statistics give similar results to those of the ADF test. All variables except $L N M B$ are nonstationary in levels but stationary in first differences. Even the variable $L N R M$ is now stationary when considering trends (in first differences). Thus, all money multipliers except for $K 1 M B$ are shown to be unstable and non-stationary. For the money multiplier $K 1 M B$, the ADF and PP test statistics give conflicting results concerning stationarity.

Table 2: ADF Unit Root Tests

\begin{tabular}{|c|c|c|c|c|}
\hline \multirow[b]{2}{*}{ Variable } & \multicolumn{2}{|c|}{ ADF test (in levels) } & \multicolumn{2}{|c|}{ ADF test (in first differences) } \\
\hline & Constant & Constant \& Trend & Constant & Constant \& Trend \\
\hline K1RM & $-1.743789(0)$ & $-3.444001(1)$ & $-6.707528(1)^{*}$ & $-6.632154(1)^{*}$ \\
\hline $\mathrm{K} 1 \mathrm{MB}$ & $-3.190790(1)^{* *}$ & $-3.247615(1)$ & $-7.135625(1)^{*}$ & $-7.080344(1)^{*}$ \\
\hline K2RM & $-1.082400(0)$ & $-1.379562(0)$ & $-6.736592(0)^{*}$ & $-6.694043(0)^{*}$ \\
\hline $\mathrm{K} 2 \mathrm{MB}$ & $-1.841135(2)$ & $-1.878191(2)$ & $-7.873974(1)^{*}$ & $-7.824324(1)^{*}$ \\
\hline K2YRM & $-1.492278(0)$ & $-0.230163(0)$ & $-5.865470(0)^{*}$ & $-5.981916(0)^{*}$ \\
\hline K2YMB & $-1.773689(2)$ & $-1.761816(2)$ & $-7.361307(1)^{*}$ & $-7.335931(1)^{*}$ \\
\hline LNRM & $-1.277912(4)$ & $-0.596146(4)$ & $-1.560926(3)$ & $-1.834635(3)$ \\
\hline LNMB & $-0.745827(1)$ & $-5.151247(0) *$ & $-10.88631(0)^{*}$ & $-10.79693(0)^{*}$ \\
\hline LNM1 & $-1.288378(0)$ & $-0.077653(0)$ & $-6.357915(0) *$ & $-6.529371(1)^{*}$ \\
\hline LNM2 & $-1.324579(1)$ & $0.018138(1)$ & $-4.671562(0)^{*}$ & $-4.886229(0)^{*}$ \\
\hline LNM2Y & $-1.753907(1)$ & $0.609820(1)$ & $-3.123774(0)$ & $-3.668400(0)^{* *}$ \\
\hline
\end{tabular}

MacKinnon (1996: 601-618) critical values (the notations * and ** indicate the rejection of the null hypothesis of a unit root at the $\% 1$ and $\% 5$ levels, respectively):

\begin{tabular}{|c|c|c|}
\hline & Constant & Constant \& Trend \\
\hline$\% 11$ & -3.54 & -4.12 \\
\hline$\% 5$ level & -2.91 & -3.49 \\
\hline
\end{tabular}


Table 3: PP Unit Root Tests

\begin{tabular}{|c|c|c|c|c|}
\hline \multirow[b]{2}{*}{$\underline{\text { Variable }}$} & \multicolumn{2}{|c|}{ PP test (in levels) } & \multicolumn{2}{|c|}{ PP test (in first differences) } \\
\hline & Constant & Constant \& Trend & $\underline{\text { Constant }}$ & Constant \& Trend \\
\hline $\begin{array}{l}\text { K1RM } \\
\text { K1MB } \\
\text { K2RM } \\
\text { K2MB } \\
\text { K2YRM } \\
\text { K2YMB } \\
\text { LNRM } \\
\text { LNMB } \\
\text { LNM1 } \\
\text { LNM2 } \\
\text { LNM2Y }\end{array}$ & $\begin{array}{l}-1.769448(5) \\
-2.680003(3) \\
-1.086891(2) \\
-2.298348(6) \\
-1.467506(3) \\
-2.139433(5) \\
-1.600426(2) \\
-0.704379(11) \\
-1.287527(3) \\
-1.390681(4) \\
-2.221160(4)\end{array}$ & $\begin{array}{c}-2.722145(4) \\
-2.708901(3) \\
-1.379562(0) \\
-2.445277(6) \\
-0.660291(3) \\
-2.239733(4) \\
0.539265(1) \\
-5.139120(1)^{*} \\
-0.076553(3) \\
0.145068(4) \\
1.822212(3)\end{array}$ & $\begin{array}{c}-8.240509(18)^{*} \\
-7.082438(12)^{*} \\
-6.681821(4)^{*} \\
-8.842684(36)^{*} \\
-5.825042(2)^{*} \\
-6.939137(16)^{*} \\
-6.312571(1)^{*} \\
-16.60489(12)^{*} \\
-6.287840(4)^{*} \\
-4.713148(1)^{*} \\
-3.105590(6)^{* *}\end{array}$ & $\begin{array}{c}-8.645143(19)^{*} \\
-7.011441(12)^{*} \\
-6.627602(4)^{*} \\
-9.370223(37)^{*} \\
-6.002343(1)^{*} \\
-7.108743(17)^{*} \\
-6.534226(0)^{*} \\
-16.43237(12)^{*} \\
-6.397743(5)^{*} \\
-4.933123(1)^{*} \\
-3.588546(6)^{* *}\end{array}$ \\
\hline \multicolumn{5}{|c|}{$\begin{array}{l}\text { MacKinnon (1996: 601-618) critical values (the notations * and } * * \text { indicate the rejection of the null hypothesis of a unit root at the } \\
\% 1 \text { and } \% 5 \text { levels, respectively): }\end{array}$} \\
\hline $\begin{array}{l}\% 1 \text { level } \\
\% 5 \text { level }\end{array}$ & $\begin{array}{l}\text { Constant } \\
-3.54 \\
-2.91\end{array}$ & $\begin{array}{l}\text { Constant \& Trend } \\
-4.12 \\
-3.49\end{array}$ & & \\
\hline
\end{tabular}

The unit root tests do not give robust results concerning the stationarity of the variables in logarithms. The ADF test statistics indicates that the variable $L N R M$ is not stationary in both level and first differenced form, while the PP test statistics indicates that the same variable is stationary in the first differenced form. In addition, the variable $L N M B$ shows contradictory results depending on whether the trend effect is included in the level form. To facilitate the remainder of the empirical analysis, all variables in logarithmic form are assumed to contain a unit root, and to be non-stationary in their level forms but stationary in their first differenced forms, enabling the model test for cointegration. This assumption would not create a serious problem for the variables used, other than the variable $L N M B$. Thus, the general results of the analysis would not be impacted by this assumption.

\section{Co-Integration Tests For Long Run Relationships}

The potential for long run co-integrating relationship between the variables is examined by using two likelihood test statistics offered by Johansen and Juselius (1990: 169-210). The first one tests for the as maximum eigenvalue for the null hypothesis of $r$ versus the alternative of $r+1$ co-integrating relationships and the second one traces for the null hypothesis of $r$ co-integrating relations against the alternative of $k$ co-integrating relations, for $r=$ $0,1, \ldots, k-1$, where $k$ is the number of endogenous variables. The versions of these two tests that are appropriate for this study are the maximum eigenvalue and trace tests with a linear deterministic trend restricted in co-integrating analysis, that is, both intercept/constant and trend in the co-integration equation versus only intercept/constant term and no trend in VAR. The critical values and their probabilities at the 0.05 significance level, when choosing the rank, are taken from MacKinnon, Haug and Michelis (1999: 563-577). These values are also available from the VAR and COINT procedures in Eviews 5.0.

The co-integration test results are presented at Table 4 below. The only significant long run co-integrating vector found is between the variables $L N M 1$ and $L N R M$ when using the maximum eigenvalue test. However, this relationship is rejected under the trace test. Tests between all other variables show no significant relationships. Thus, there are no co-integrating relationships between base money stocks that are under the control of the CBRT and various money supply amounts that are created though the money multiplier process and by other economic agents in the Turkish economy. The only significant relationship found is between the $M I$ aggregate and reserve money, two final money supply measures that result after the money multiplier process has taken place. These results are in line with the money multiplier stationarity test results shown in Tables 2 and 3. 
Table 4: Co-Integration Analysis Between The Sub-Determinants Of Money Multipliers

SERIES: LNM1; LNRM [Lag interval (in first differences): 1 to 5]

\begin{tabular}{|c|c|c|c|c|}
\hline Hypothesized & & Trace & 0.05 & \\
\hline No. of CE(s) & Eigenvalue & Statistic & Critical Value & Prob. $^{* *}$ \\
\hline None & 0.314376 & 25.05787 & 25.87211 & 0.0629 \\
\hline At most 1 & 0.039408 & 2.41233 & 12.51798 & 0.9378 \\
\hline Hypothesized & & Max-Eigen & 0.05 & \\
\hline No. of $\mathrm{CE}(\mathrm{s})$ & Eigenvalue & $\underline{\text { Statistic }}$ & Critical Value & Prob. $^{* *}$ \\
\hline None $^{*}$ & 0.314376 & 22.64553 & 19.38704 & 0.0162 \\
\hline At most 1 & 0.039408 & 2.41233 & 12.51798 & 0.9378 \\
\hline
\end{tabular}

Maximum eigenvalue test indicates 1 co-integrating equation at the 0.05 level.

Normalized co-integrating coefficients (standard error in parentheses):

$\begin{array}{lll}\text { LNM1 } & \text { LNRM } & \text { @ TREND } \\ -1.000000 & 1.064636 & 0.005682 \\ & (0.05552) & (0.00735)\end{array}$

Adjustment coefficients (standard error in parentheses):

D(LNM1) $\quad-0.606697 \quad \mathrm{D}(\mathrm{LNRM}) \quad 0.017440$
$(0.205860)$
$(0.185610)$

${ }^{*}$ denotes rejection of the hypothesis at the 0.05 level

** MacKinnon-Haug-Michelis (1999) p-values

SERIES: LNM1; LNMB [Lag interval (in first differences): 1 to 1]

\begin{tabular}{|c|c|c|c|c|}
\hline \multicolumn{2}{|l|}{ Hypothesized } & Trace & \multicolumn{2}{|l|}{0.05} \\
\hline No. of CE(s) & Eigenvalue & $\underline{\text { Statistic }}$ & Critical Value & Prob. $^{* *}$ \\
\hline None & 0.253228 & $\overline{18.96541}$ & 25.87211 & $\overline{0.2828}$ \\
\hline At most 1 & 0.023806 & 1.44566 & 12.51798 & 0.9924 \\
\hline Hypothesized & & Max-Eigen & 0.05 & \\
\hline No. of CE(s) & Eigenvalue & Statistic & Critical Value & Prob. ${ }^{* *}$ \\
\hline None & 0.253228 & $\overline{17.51974}$ & 19.38704 & 0.0915 \\
\hline At most 1 & 0.023806 & 1.44566 & 12.51798 & 0.9924 \\
\hline
\end{tabular}

Both Trace and Maximum eigenvalue tests indicate no co-integration at the 0.05 level.

Normalized co-integrating coefficients (standard error in parentheses):

$\begin{array}{lll}\text { LNM1 } & \text { LNRM } & \text { @ TREND } \\ -1.000000 & -1.642365 & 0.340126 \\ & (0.35143) & (0.04541)\end{array}$

Adjustment coefficients (standard error in parentheses):

$\begin{array}{llll}\mathrm{D}(\mathrm{LNM} 1) & -0.013601 & \mathrm{D}(\mathrm{LNRM}) & -0.424182 \\ & (0.015620) & & (0.098700)\end{array}$

* denotes rejection of the hypothesis at the 0.05 level

${ }^{* * *}$ MacKinnon-Haug-Michelis (1999) p-values 
SERIES: LNM2; LNRM [Lag interval (in first differences): 1 to 5]

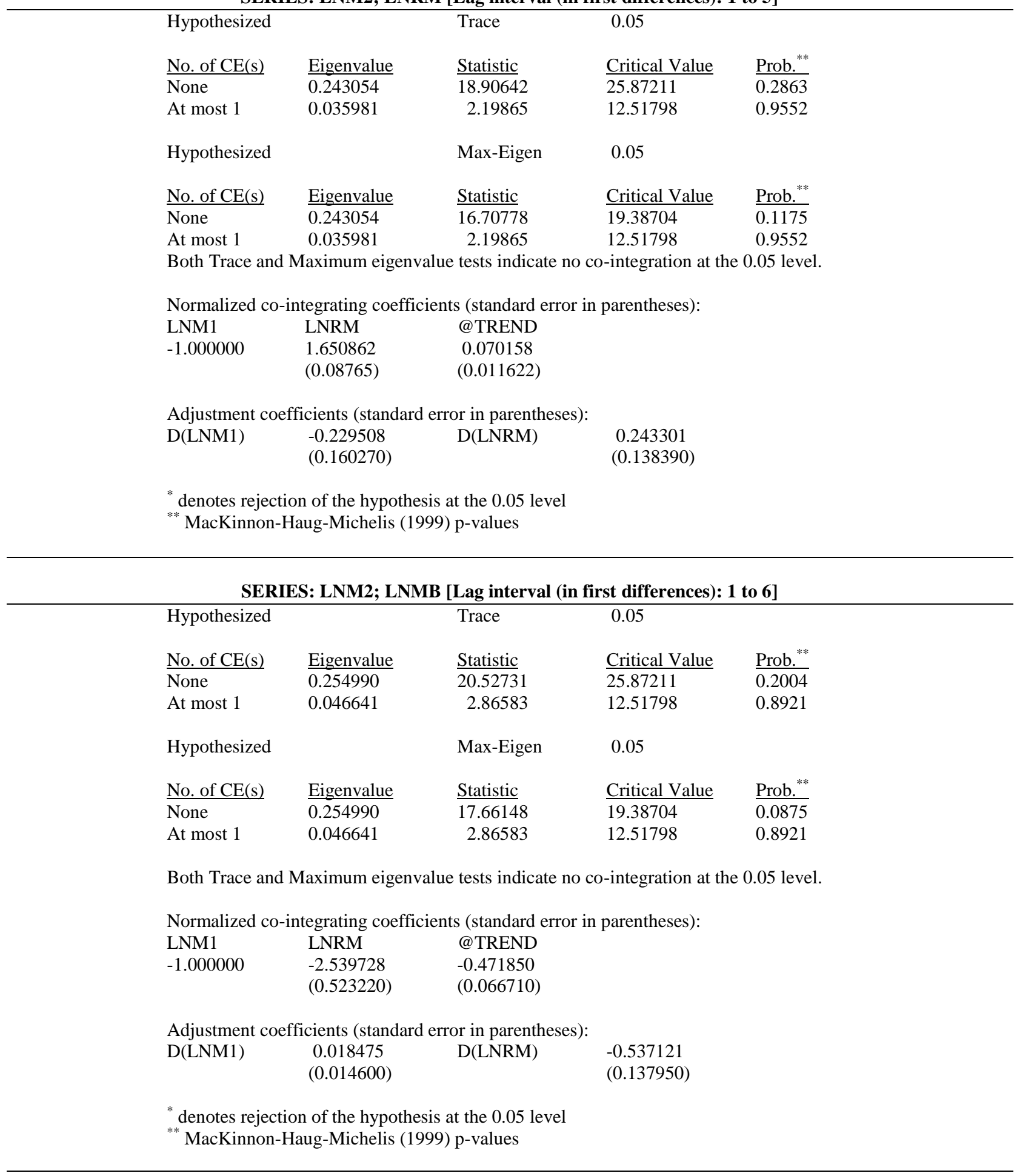


SERIES: LNM2Y; LNRM [Lag interval (in first differences): 1 to 3]

\begin{tabular}{|c|c|c|c|c|}
\hline \multicolumn{2}{|l|}{ Hypothesized } & Trace & \multicolumn{2}{|l|}{0.05} \\
\hline No. of CE(s) & Eigenvalue & $\underline{\text { Statistic }}$ & Critical Value & Prob. ${ }^{* *}$ \\
\hline None & 0.143467 & 11.47761 & 25.87211 & 0.8466 \\
\hline At most 1 & 0.035775 & 2.18584 & 12.51798 & 0.9561 \\
\hline Hypothesized & & Max-Eigen & 0.05 & \\
\hline No. of CE(s) & Eigenvalue & Statistic & Critical Value & Prob. ${ }^{* *}$ \\
\hline None & 0.143467 & 9.291778 & 19.38704 & 0.6741 \\
\hline At most 1 & 0.035775 & 2.185837 & 12.51798 & 0.9561 \\
\hline
\end{tabular}

Both Trace and Maximum eigenvalue tests indicate no co-integration at the 0.05 level.

Normalized co-integrating coefficients (standard error in parentheses):

$\begin{array}{lcc}\text { LNM1 } & \text { LNRM } & \text { @ TREND } \\ -1.000000 & 1.822975 & -0.087758 \\ & (0.26218) & (0.03498)\end{array}$

Adjustment coefficients (standard error in parentheses):

$\begin{array}{llll}\mathrm{D}(\mathrm{LNM} 1) & -0.038944 & \mathrm{D}(\mathrm{LNRM}) & 0.119168 \\ & (0.051020) & & (0.050260)\end{array}$

${ }^{*}$ denotes rejection of the hypothesis at the 0.05 level

** MacKinnon-Haug-Michelis (1999) p-values

SERIES: LNM2Y; LNMB [Lag interval (in first differences): 1 to 2]

\begin{tabular}{|c|c|c|c|c|}
\hline \multicolumn{2}{|l|}{ Hypothesized } & Trace & \multicolumn{2}{|l|}{0.05} \\
\hline No. of CE(s) & Eigenvalue & $\underline{\text { Statistic }}$ & Critical Value & Prob. $^{* *}$ \\
\hline None & 0.171826 & 16.26400 & 25.87211 & 0.4716 \\
\hline At most 1 & 0.079220 & 4.95208 & 12.51798 & 0.6033 \\
\hline Hypothesized & & Max-Eigen & 0.05 & \\
\hline No. of CE(s) & $\underline{\text { Eigenvalue }}$ & $\underline{\text { Statistic }}$ & $\underline{\text { Critical Value }}$ & Prob. $^{* *}$ \\
\hline None & 0.171826 & 11.31191 & 19.38704 & 0.4817 \\
\hline At most 1 & 0.079220 & 4.95208 & 12.51798 & 0.6033 \\
\hline
\end{tabular}

Both Trace and Maximum eigenvalue tests indicate no co-integration at the 0.05 level.

Normalized co-integrating coefficients (standard error in parentheses):

$\begin{array}{lll}\text { LNM1 } & \text { LNRM } & \text { @ TREND } \\ -1.000000 & -155.3802 & 19.27348 \\ & (46.5626) & (5.86990)\end{array}$

Adjustment coefficients (standard error in parentheses):

$\begin{array}{llll}\mathrm{D}(\mathrm{LNM} 1) & -0.000108 & \mathrm{D}(\mathrm{LNRM}) & -0.003778 \\ & (0.000130) & & (0.001220)\end{array}$

${ }_{* *}^{*}$ denotes rejection of the hypothesis at the 0.05 level

${ }^{* * *}$ MacKinnon-Haug-Michelis (1999) p-values 
The empirical results in Tables 2-4 show that the money multipliers dominating the money markets during the investigation period are unstable and do not support a monetarist explanation how the money markets in Turkey operate. Thus, the conditions for implementing an effective monetary policy do not exist in the Turkish economy during 1990-2004.

\section{SUMMARY AND CONCLUDING COMMENTS}

A basic tenet of monetary theory is that the monetary authority can control the monetary aggregates and forecast their growth paths. Under these conditions, implementing the monetary policy would proceed in accordance with ex-ante expectations, provided that the behavior of the money multipliers are stable and that there are predictable, long run relationships between the final money supply, other economic variables, and the sub-components of these multipliers.

This paper investigates whether this stability condition exists for the period of $1990-2004$ in the Turkish economy. In addition, the stability of various money multipliers and potential long run co-integrating relationships between the sub-components of these multipliers and several money supply measures are examined. The results shows that the processes that extend the basic money supply to the final monetary aggregates are unstable, decreasing the effectiveness of monetary policies implemented by the CBRT. In addition, the co-integration analyses show that there are no long run relationships between the sub-components of money multipliers and money supply measures, indicating that traditional monetary theory prescriptions cannot be used to implement monetary policy in Turkey.

\section{SUGGESTIONS FOR FUTURE RESEARCH}

Future studies can analyze the impact of the changes in the base money stock on the level of inflation rates. In addition, the study period can be lenghten to include several decades of data. This study can be repeated to examine the dominant money multiplier process by itself, to obtain more accurate policy implementation recommendations for the CBRT. In addition, future studies may be conducted in countries other than Turkey to determine if the lack of stability and monetary policy effectiveness observed in Turkey are common in other developing countries. Finally, future studies may use our methodology and determine if our results can be duplicated to ensure the accuracy of our findings that are contrary to the results of studies conducted in developed countries.

\section{REFERENCES}

1. Begg, D., Fischer, S., and Dornbusch, R., Economics, New York: McGraw-Hill, Fourth Ed., 1994.

2. Dickey, D. A. and Fuller, W. A., Distribution of the Estimators for Autoregressive Time Series with a Unit Root, Journal of American Statistical Association, Vol. 74, No. 366, (June 1979), pp. 427-431.

3. Dickey, D. A., Jansen, D. W., and Thornton, D. L., A Primer on Co-integration with an Application to Money and Income, Federal Reserve Bank of St. Louis Review, (March/April 1991), pp. 58-78.

4. Engle, R. F. and Granger, C. W. J. Co-integration and Error Correction: Representation, Estimation, and Testing, Econometrica, Vol. 55, No. 2, (March 1987), pp. 251-276.

5. Friedman, M., The Role of Monetary Policy, The American Economic Review, Vol. 58, No. 1,(1968), pp. 117.

6. Gonzalo, J., Five Alternative Methods of Estimating Long-Run Equilibrium Relationships, Journal of Econometrics, Vol. 60, (1994), pp. 203-233.

7. Johansen, S., Estimation and Hypothesis Testing of Co-integration Vectors in Gaussian Vector Autoregressive Models, Econometrica, Vol. 59, (1991), pp. 1551-1580.

8. Johansen, S., Likelihood-based Inference in Co-integrated Vector Autoregressive Models, Oxford University Press, 1995.

9. Johansen, S. and Juselius, K., Maximum Likelihood Estimation and Inference on Co-integration with Applications to the Demand for Money, Oxford Bulletin of Economics and Statistics, Vol. 52, (1990), pp. 169-210.

10. Keyder, N., Para,Teori,Politika,Uygulama, Sixth Ed., Beta Dağıtım, 1998. 
11. MacKinnon, J. G., Numerical Distribution Functions for Unit Root and Co-integration Tests, Journal of Applied Econometrics, Vol. 11, (1996), pp. 601-618.

12. MacKinnon, J. G., Haug, A. A., and Michelis, L., Numerical Distribution Functions of Likelihood Ratio Tests for Co-integration, Journal of Applied Econometrics, Vol. 14, (1999), pp. 563-577.

13. Mishkin, F. S., The Economics of Money, Banking, and Financial Markets, Fifth ed., New York: McGrawHill, 1997.

14. Paya, M., Para Teorisi ve Para Politikasl, Istanbul: Filiz Publishing, 1998.

15. Phillips, P. C. B. and Perron, P., Testing for a Unit Root in Time Series Regression, Biometrika, Vol. 75, (1988), pp. 335-346.

16. QMS, Eviews 5 User's Guide, (April 2004).

17. Şahinbeyoğlu, G., The Stability of Money Multiplier: A Test for Co-integration, CBRT Research Department Working Paper, No: 9603, (December 1995). 